\title{
Breast-feeding and the working mother in Nairobi
}

\author{
Alice Lakati ${ }^{1}$, Colin Binns ${ }^{2, *}$ and Mark Stevenson ${ }^{2}$ \\ 'Kenya Medical Training College, Nairobi, Kenya: ${ }^{2}$ School of Public Health, Curtin University, GPO Box U 1987, \\ Perth, Western Australia 6845, Australia
}

Submitted 17 October 2001: Accepted 28 March 2002

\begin{abstract}
Objective: In the fast growing city of Nairobi, women often combine the roles of mother and worker in trying to achieve better standards of living. The objective of this study was to document the effect of returning to work on breast-feeding by mothers in Kenya.

Design: A cross-sectional survey.

Setting: Outpatient clinics of two major hospitals in Nairobi, one government hospital in an economically deprived area and one high-fee private hospital.

Subjects: Four hundred and forty-four working mothers from low and higher socioeconomic areas in Nairobi. All working mothers with infants aged 4 to 12 months attending during the survey period were invited to participate.

Results: The prevalence of breast-feeding at the time of interview was found to be 94.1\%. The lower socio-economic group exhibited a higher prevalence of breastfeeding (99\%), 10\% greater than the higher socio-economic group. The mean number of hours the mothers were away from home due to work was 46.2 hours each week. The majority (54.4\%) of the mothers employed a 'house-girl' to care for their infant while they were at work, while $28.4 \%$ were able to take their infants to work. Most of the breast-feeding mothers (95\%) breast-fed their infants at least three times a day and only 23 mothers reported not being able to breast-feed their infants during the day. The lower socio-economic group had a mean of 5.09 breast-feeding times per day while the higher socio-economic group had a mean of 3 times a day. In a logistic regression analysis the mode of work (fixed working hours vs. shift working hours) was associated with exclusive breast-feeding at one month (odds ratio $(\mathrm{OR})=0.45$ ) and two months (OR $=0.39)$.

Conclusion: In Western countries 'return to work' is often cited as the reason that breast-feeding is discontinued prematurely. In this study we have shown how mothers in Kenya are able to successfully continue breast-feeding after they have returned to work, often for very long hours.
\end{abstract}

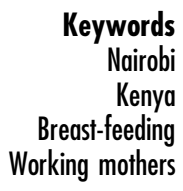

The promotion of breast-feeding is a global priority, because of its many benefits to infant and mother ${ }^{1,2}$. However, it is often difficult for mothers working outside the home to continue to breast-feed, and return to work is cited as a major reason for the decision to cease breastfeeding ${ }^{3}$. In many developing countries, labour force participation by women of childbearing years has increased rapidly, posing new challenges for women attempting to combine their roles as workers and mothers. In the rapidly modernising city of Nairobi, economic pressures are such that more women have taken up either paid employment or are self-employed. The World Health Organization ${ }^{4,5}$ maintains that: 'the successful integration of women's productive and reproductive roles is the basis for child survival and economic development'.

Employed women are important role models for women in their communities, in their breast-feeding and general health behaviour. They constitute a major reservoir of knowledge and skills and their participation in national development is very important ${ }^{6}$. They are perceived as better-educated and as full participants of the 'modern' sector of the society, and their behaviour greatly influences their rural counterparts. For these reasons it was important to study how mothers in Nairobi combine work and breast-feeding.

\section{Method}

A study was undertaken of working mothers from high and low socio-economic areas in Nairobi, Kenya, who had infants aged between 4 months and 12 months. Mothers attending the private hospital, where substantial fees are paid, were classified as the higher socio-economic group, while mothers attending the government hospital were classified as the lower socio-economic group. All mothers attending the maternal and child health clinics during a 
six-week period were asked if they worked outside their home. All working mothers, 200 from the government hospital and 244 from the private hospital, were then invited to participate in the survey.

Structured interviews were held with each working mother, with infants aged 4 to 12 months old, after the babies had been weighed, while they waited to see medical staff. The questionnaire was designed to identify feeding methods and collect information on characteristics known or thought to be associated with breast-feeding among working mothers.

The study was approved by the Office of the President, Republic of Kenya and the Human Research Ethics Committee of Curtin University.

All data were coded and checked and then analysed using the Statistical Package for Social Sciences (SPSS for Windows, version 10).

\section{Results}

The majority of the mothers were married (91\%) and no differences were evident between the higher and lower socio-economic groups in relation to marital status, gender of the baby or the baby's age at the time of interview (mean age, 28 weeks) (Table 1).

Overall, $53 \%$ of the mothers were self-employed and $47 \%$ were in formal employment. Self-employed mothers commonly spent their day selling at the market or in the retail sector. Seventy-one per cent of the mothers from the higher socio-economic group were in formal paid employment compared with only 19\% from the lower socio-economic group $\left(\chi^{2}=117.2, \mathrm{df}=1, P=0.000\right.$, $n=442)$. There were significant differences among the two groups as to whether they worked on shift or for fixed hours $\left(\chi^{2}=6.112\right.$, df $\left.=1, P=0.013, n=443\right)$, with $14.4 \%$ of the mothers from the higher socio-economic group working shift hours as opposed to only $7 \%$ in the lower socio-economic group.

There was a wide variation in the number of hours the mothers worked in a week, including travelling time. The hours worked ranged from 12 to 93 (mean $46.2 \pm 13.42$ hours). Mothers from the higher socio-economic group worked significantly longer, a mean of 48.3 hours compared with 43.3 hours in the lower socio-economic group ( $t$-test: $\left.\chi^{2}=4.166, \mathrm{df}=442, \quad P=0.000\right)$, but worked for slightly fewer days, a mean of 5.47 days vs. 5.97 days.

At the time of interview $94.1 \%$ of the mothers were breast-feeding and at six months of age the prevalence was $92.2 \%$ (95\% confidence interval (CI) 89.1-95.3\%), $98.4 \%$ among the lower socio-economic group and $87.1 \%$ among the higher socio-economic group.

The main reason the mothers gave for breast-feeding was because it is 'the best way to feed the baby' (47.8\%); other reasons were 'baby is still young' and the influence of health professionals. Significant differences between the two groups were evident, with $56.4 \%$ in the higher socio-economic group indicating they breast-fed because it is 'the best way to feed the baby' compared with $38.4 \%$ in the lower socio-economic group. In the lower socioeconomic group, $40.4 \%$ indicated that they breast-fed their infants because 'the baby is still young', compared with 5\% in the higher socio-economic group $\left(\chi^{2}=82.257, \mathrm{df}=3\right.$, $P=0.000)$.

During the day (lunchtime) only $29.7 \%$ of the mothers from the higher socio-economic group fed their babies compared with $79.4 \%$ from the lower socio-economic group (see Fig. 1). Other times of the day were almost identical: morning, $96.5 \%$ vs. $94.5 \%$; evening, $94.0 \%$ vs. 91.8\%; night, $97.0 \%$ vs. $95.9 \%$ (lower socio-economic status vs. higher socio-economic status, respectively).

Mothers from the lower socio-economic group were far more likely to take their infants to work with them than mothers in the higher socio-economic group $(53.1 \% \mathrm{vs}$. $7.8 \%, \chi^{2}=166.069$, df $\left.=1, P=0.000\right)$.

While they were at work mothers from the higher socioeconomic group were more likely feed their infants with cow's milk (43.1\%) than the lower socio-economic group (Table 2).

Only three mothers $(0.7 \%)$, all from the higher socioeconomic group, did not share the same bedroom as their infant. Of the remaining mothers who shared the same room, $97.5 \%$ in the lower socio-economic group also shared the same bed compared with $61.4 \%$ in the higher socio-economic group $\left(\chi^{2}=82.361\right.$, df $\left.=1, P=0.000\right)$. Among the breast-feeding mothers, only one mother $(0.5 \%, n=198)$ from the lower socio-economic status group and seven mothers $(3.2 \%, n=220)$ from the higher socio-economic status group indicated they did not breastfeed during the night.

The number of times the mothers breast-fed at night did

Table 1 Baby's carer by socio-economic status

\begin{tabular}{lccc}
\hline Variable & $\begin{array}{c}\text { Lower } \\
\text { socio-economic } \\
\text { group (\%) }(n=200)\end{array}$ & $\begin{array}{c}\text { Higher } \\
\text { socio-economic } \\
\text { group (\%) }(n=244)\end{array}$ \\
\hline Baby carer & & & \\
Always with baby & 54.3 & 7.4 & $\chi^{2}=205.518$, df $=3, P=0.000(n=443)$ \\
House-girl & 17.1 & 84.8 & \\
Relative & 16.6 & 5.3 & \\
Other & 12.1 & 2.5 & \\
\hline
\end{tabular}




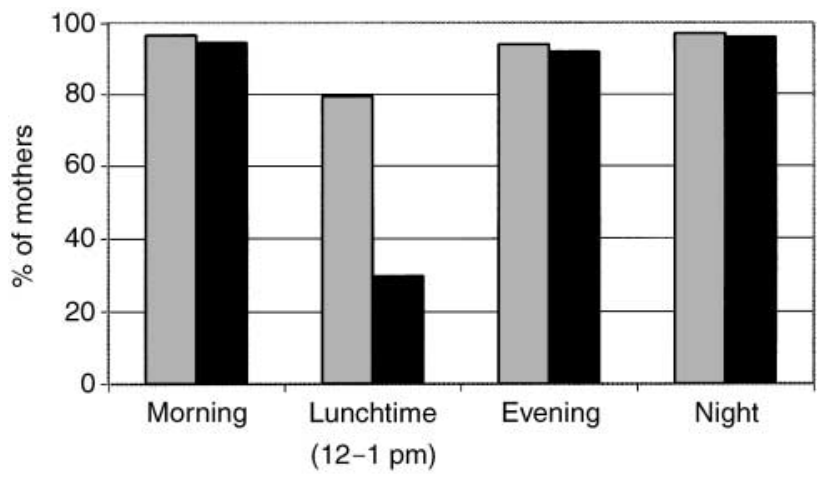

aLow socio-economic status $\mathbf{m i g h}$ socio-economic status

Fig. 1 Times of the day when the mothers breast-fed

not differ between the two groups. Continuous breastfeeding throughout the night was practised by $14 \%$ of mothers.

At one month and two months after birth, the mode of work (fixed working hours as opposed to shift work) was found to be associated with exclusive breast-feeding (odds ratio $(\mathrm{OR})=0.451,95 \% \mathrm{CI} 0.243-0.836$ and $\mathrm{OR}=0.39$, 95\% CI 0.206-0.738, respectively), after controlling for other variables (socio-economic status, employment, working days and working hours).

\section{Discussion}

The mothers in this study were very successful at breastfeeding, as the breast-feeding initiation was 99.8\%, and only one mother did not attempt breast-feeding. At six months the prevalence was 92.2\% (95\% CI 89.1-95.3\%). These results are comparable with the Kenyan rate reported by the United Nations International Childrens Fund of 94\% at 6-9 months ${ }^{7}$ and to the rates in the urban areas of other developing countries ${ }^{8}$, although rates in Chiang Mai, Thailand were slightly lower?

In this study the lower socio-economic group had a higher breast-feeding rate, in contrast with reports from the developed world, where extended breast-feeding is more common among the well-educated, upper socioeconomic group ${ }^{10}$. However, in developing countries, particularly Asia and Africa, the converse is usually true, and extended breast-feeding is more predominant amongst poor, less-educated women ${ }^{11-13}$.

Mothers from the higher socio-economic group were more likely to be in formal paid employment, while mothers from the lower socio-economic group were more likely $(53.1 \%)$ to take their infants to work, therefore allowing them more time to breast-feed $\left(\chi^{2}=166.069\right.$, $\mathrm{df}=1, P=0.000)$. The higher socio-economic mothers usually employed a 'house-girl' as a carer.

There are few studies available from developing countries with which to compare these data. In Indonesia, Launer undertook a qualitative study among the Madura agricultural community ${ }^{14}$. He reported that women who
Table 2 Infant's main food while the mother is at work by socioeconomic group

\begin{tabular}{lcc}
\hline Food & Higher (\%) & Lower (\%) \\
\hline Cow's milk & 43.1 & 18.7 \\
Expressed breast-milk & 4.6 & 0.5 \\
Formula & 9.6 & 0.5 \\
Porridge & 25.5 & 44.6 \\
Breast-feeding & 2.9 & 10.9 \\
Other foods & 14.2 & 24.9 \\
\hline
\end{tabular}

worked in agriculture during early infancy either brought their infants to the fields or worked within earshot so that they could return quickly to their infants.

Employment has been reported to have a negative association with breast-feeding. In Nigeria, Bamisaiye and Oyediran found an inverse relationship between employment and the duration of breast-feeding ${ }^{6}$. A survey of employed and unemployed mothers in the USA reported that maternal employment was not related to initiation of breast-feeding, but returning to work within one year of delivery was associated with shorter duration of breastfeeding ${ }^{3}$. Our present study did not show a significant association between employment and duration of breastfeeding. The mothers in this study were generally able to find ways of successfully combining work and breastfeeding.

Yeung et al. indicated that mothers who choose to breast-feed are knowledgeable of its advantages and want to nurse their infants ${ }^{15}$. In this study the main reasons reported for breast-feeding were because it is 'the best way to feed the baby', 'the baby is still young' or 'advice from the health professional' and because 'I love my baby'. Significant differences between the two groups were evident as to why they breast-feed. The higher socioeconomic group mainly (56.4\%) indicated that it is the best way to feed the baby' while only $38.4 \%$ in the lower socio-economic group gave this reason. Forty per cent in the lower socio-economic group breast-feed simply because 'the baby is still young'. Mothers from the lower socio-economic group perceived breast-feeding as a natural function and the only way to feed/nourish the infant before they are of age to feed totally on their own. It is likely that economic factors reinforced this practice.

Another factor that could have contributed to the higher prevalence of breast-feeding in this study is the fact that mothers slept in the same room as their infants. Only three (0.7\%) mothers, all from the higher socio-economic group, did not share the same room as their infants. Few studies have reported on this issue, but one recent study from New Zealand demonstrated an association with sleeping in the same room and longer duration of breast-feeding ${ }^{16}$. Sharing the same room and/or bed as their infant enabled the Nairobi mothers to breast-feed at night, and most of the mothers reported breast-feeding on demand throughout the night.

After controlling for other variables in the model, 
working fixed hours as opposed to shift hours was significantly associated with exclusive breast-feeding at one month (OR $=0.45,95 \% \mathrm{CI} 0.24-0.84)$ as well as at two months (OR $=0.39$, 95\% CI 0.21-0.73). No other studies have reported this association with exclusive breast-feeding. However, Yimyam et al. in a qualitative analysis quoted mothers with irregular working hours as expressing frustration about maintaining breast-feeding?

Breast-feeding in Nairobi, Kenya is acknowledged as the superior method of feeding infants and remains almost universal among this group of working mothers. This study has demonstrated that working mothers, who return to work after their child has been born, can successfully breast-feed, often while working very long hours. In Western countries 'return to work' is often cited as the reason that breast-feeding is discontinued prematurely. The working mothers in Nairobi are committed to breastfeeding and have shown that breast-feeding is physiologically possible under these circumstances. They have set an example for other countries to follow.

\section{Acknowledgements}

Ms Lakati was supported by a scholarship provided by AusAID, the overseas aid organisation of the Australian Government.

\section{References}

1 Dobson B, Murtaugh M. Position of the American Dietetic Association: Breaking the barriers to breastfeeding. J. Am. Diet. Assoc. 2001; 101(10): 1213-20.

2 National Health and Medical Research Council. Infant Feeding Guidelines for Health Workers. Canberra: National Health \& Medical Research Council, 1996.
3 Visness C, Kennedy K. Maternal employment and breastfeeding: findings from the 1988 National Maternal and Infant Health Survey. Am. J. Public Health 1997; 87(6): 945-50.

4 World Health Organization (WHO). Breastfeeding: The Technical Basis and Recommendations for Action. Geneva: WHO, 1993.

5 World Health Organization (WHO). Infant and Young Child Nutrition. Progress and Evaluation Report; and Status of Implementation of the International Code of Marketing of Breast-milk Substitutes. Report by the Director-General at the Forty-seventh World Health Assembly. Geneva: WHO, 1994.

6 Bamisaiye A, Oyediran M. Breastfeeding among female employees at a major health institution in Lagos, Nigeria. Soc. Sci. Med. 1983; 17(23): 1867-71.

7 United Nations International Childrens Fund (UNICEF). The Progress of Nations. Geneva: UNICEF, 1999.

8 Winikoff B, Laukaran V. Breast feeding and bottle feeding controversies in the developing world: evidence from a study in four countries. Soc. Sci. Med. 1989; 29(7): 859-68.

9 Yimyam S, Morrow M, Srisuphan W. Role of conflict and rapid socio-economic change: breastfeeding among employed women in Thailand. Soc. Sci. Med. 1999; 49: 957-65.

10 Scott JA, Binns CW. Breastfeeding in Perth - recent trends. Aust. N.Z. J. Public Health 1996; 20(2): 210-1.

11 Hull V, Thapa S, Pratomo H. Breast-feeding in the modern health sector in Indonesia: the mother's perspective. Soc. Sci. Med. 1990; 30(5): 625-33.

12 Prentice A. Extended breast-feeding and growth in rural China. Nutr. Rev. 1994; 52(4): 144-6.

13 Forman M. Review of research on the factors associated with choice and duration of infant feeding in less developed countries. Pediatrics 1984; 74: 667-70.

14 Launer L. The work patterns of lactating women in Madura. Soc. Sci. Med. 1993; 37(4): 555-63.

15 Yeung D, Pennell M, Leung M, Hall J. Breastfeeding: prevalence and influencing factors. Can. J. Public Health 1981; 72: 323-30.

16 Vogel A, Hutchison B, Mitchell E. Factors associated with the duration of breastfeeding. Acta Pediatr. 1999; 88(6): 1320-6. 